\title{
Primeiro como negação: esperança, ética do cuidado e autonomia no \#EleNão
}

\author{
Thais Marques de Santo \\ Douglas M. R. Porto ${ }^{2}$ \\ Recebido em março de 2020 \\ Aceito em junho de 2020
}

\section{RESUMO}

A principal novidade das eleições presidenciais de 2018 no Brasil foi o movimento Mulheres unidas contra Bolsonaro, tendo aglutinado em torno da consigna \#EleNão diversos setores organizados da luta feminista e milhões de mulheres sem filiação alguma, inclusive sem experiência de prática política. $O$ Movimento que nasceu nas redes sociais acumulou força e agregou mulheres de forma tão expressiva que viabilizou sua presença nas ruas e demonstrou-se capaz de realizar a difícil tarefa de agregar setores políticos que têm sido incapazes de cooperar entre si e de construir uma frente de luta ampla, unificada e, ao mesmo tempo, plural. Através de análise qualitativa, pretendemos identificar a natureza do movimento Mulheres unidas contra Bolsonaro e compreender por que foram as mulheres o principal grupo social a mobilizar-se contra o candidato do PSL.

Palavras-chave: \#EleNão; Mulheres unidas contra Bolsonaro; Ética do cuidado.

\section{First as negation: hope, ethics of care and autonomy in the \#NotHim}

\begin{abstract}
The main novelty of the 2018 presidential elections in Brazil was the movement Women united against Bolsonaro, having grouped around the slogan \#NotHim several organized sectors of the feminist struggle and millions of women without any affiliation, even without experience of political practice. The Movement that was born on social networks accumulated strength and gathered women so expressively that it made their presence on the streets viable and proved capable of accomplishing the difficult task of aggregating political sectors that have been unable to cooperate with each other and build a broad, unified and, at the same time, plural forefront of struggle. Through qualitative analysis we intend to identify the nature of the movement Women united against Bolsonaro and comprehend why the main social group that mobilized against the PSL candidate was constituted by women.
\end{abstract}

Keywords: \#NotHim; Women united against Bolsonaro; Ethics of care.

\footnotetext{
${ }^{1}$ Doutoranda no Programa de Pós-graduação em Ciências Sociais da PUCRS, Porto Alegre, Brasil, thaismsanto@gmail.com, bolsista CAPES/PROSUC.

${ }^{2}$ Doutorando no Programa de Pós-graduação em Ciências Sociais da PUCRS, Porto Alegre, Brasil, douglasrporto@gmail.com, bolsista CAPES/PROSUC.
} 


\section{Introdução}

Os eixos centrais da campanha presidencial de Jair Bolsonaro (PSL)3 eram a liberação do porte irrestrito de armas de fogo, a defesa do moralismo de costumes e propostas ultraliberais para a economia. A primeira das pautas foi atrelada a um discurso que criou um "nós", que compreende: cidadãos que trabalham, adquirem seus bens materiais e, com isso, têm o direito de zelar por eles, mesmo que custe a vida de outro ser humano; e também criou a imagem antagônica, o inimigo a ser combatido, o "eles": "vagabundos" que não trabalham, que ameaçam o patrimônio alheio e que, portanto, podem ser exterminados por um de "nós" à revelia dos valores ancorados nos direitos humanos, socialmente aceitos como válidos e positivados constitucionalmente. Inclusive, o combate aos direitos humanos tornou-se uma espécie de bandeira de luta deste candidato.

Ao maniqueísmo que dá o tom de toda a campanha de Bolsonaro está subjacente a definição da liberdade negativa como valor fundamental, que está sendo violado em função da regulação estatal do porte de armas. A liberdade negativa, noção marcadamente desenvolvida por Thomas Hobbes, em “O Leviatã”, compreende que a liberdade é "não ser obstruído por resistências externas na busca de realizar seus objetivos" (Honneth, 2015, p. 43). O direito à defesa da própria vida se converte em direito à preservação da propriedade privada em detrimento da vida do outro. Fenômeno original das sociedades modernas capitalistas, em que a alteridade é negada em nome do culto à propriedade privada e objetos em geral.

Dentre as diversas organizações e grupos sociais que se opuseram ao citado candidato, o que ganhou maior expressividade durante o período eleitoral foi o movimento Mulheres unidas contra Bolsonaro, protagonizado por mulheres de todo o Brasil que, através de um grupo fechado no Facebook, organizaram mobilizações de rua manifestando sua rejeição ao candidato do PSL, motivada por suas declarações machistas, homofóbicas, racistas e violentas contra minorias. Citamos algumas das declarações discriminatórias e violentas proferidas por Bolsonaro ao longo de sua

\footnotetext{
3 Partido Social Liberal.
} 
carreira política: "Eu jamais ia estuprar você porque você não merece”; "Foram quatro [filhos] homens. A quinta eu dei uma fraquejada, e veio uma mulher"; "Por isso o cara paga menos para a mulher [porque ela engravida]"; "O filho começa a ficar assim meio gayzinho, leva um couro, ele muda o comportamento dele. Tá certo?”; “Ele [o indígena] devia ir comer um capim ali fora para manter as suas origens"; "Fui num quilombola em Eldorado Paulista. O afrodescendente mais leve lá pesava sete arrobas. Não fazem nada! Acho que nem para procriadores servem mais"; "A escória do mundo [imigrantes] está chegando ao Brasil como se nós não tivéssemos problema demais para resolver" (CARTA CAPITAL, 2018).

O movimento Mulheres unidas contra Bolsonaro aglutinou em torno da consigna \#EleNão diversos setores organizados da luta feminista e milhões de mulheres sem filiação alguma, inclusive sem experiência de prática política. $O$ Movimento que nasceu nas redes sociais acumulou força e agregou mulheres de forma tão expressiva que viabilizou sua presença também nas ruas.

O Movimento transbordou a esfera virtual e foi capaz de mobilizar em seus atos de rua diversos setores da sociedade civil solidários à pauta do \#EleNão. Isso fez do Movimento uma das principais novidades desse pleito eleitoral. Jair Bolsonaro ter sido eleito não anula a importância do Movimento. As mulheres realizaram o que nenhuma organização política tradicional tem sido capaz de fazer: aglutinaram em torno do \#EleNão praticamente todos os setores da luta das mulheres, mulheres negras, brancas, indígenas, lésbicas, transexuais, evangélicas, católicas, de religiões de matriz africana, abastadas, trabalhadoras; feministas anarquistas, liberais, socialistas, radicais; partidos políticos que disputaram as eleições com candidaturas próprias, Partido dos Trabalhadores (PT), Partido Comunista do Brasil (PC do B), Partido Socialismo e Liberdade (PSOL), Partido Democrático Trabalhista (PDT); Movimentos Sociais, como o Movimento dos Trabalhadores Rurais Sem Terra, o Movimento dos Trabalhadores Sem Teto e o Movimento LGBT+; sindicatos; entidades de representação estudantil.

Evidencia-se na breve catalogação dos agentes que adeririam ao \#EleNão que o Movimento foi uma espécie de instância suprapartidária capaz de fazer congregar organizações políticas que, embora situadas em um mesmo campo político-ideológico, 
em função de diferenças, não cooperam entre si e nem agem de modo articulado, não raras vezes a interação entre elas é através da competição. Portanto, é sobretudo em função dessa capacidade de agregação do movimento Mulheres unidas contra Bolsonaro que o consideramos a principal novidade política dos últimos tempos no Brasil. Desde 2013 não havia surgido no cenário nacional algo relevante e fecundo para um projeto emancipatório. Também é importante frisar que se trata de um movimento distinto das organizações políticas tradicionais que, até há pouco, protagonizavam as ações na esfera política do país. Depois das eleições de 2018, não é mais possível ignorar a relevância das mulheres na esfera política ${ }^{4}$ (no sentido amplo do termo "política", isto é, a institucionalidade e, para além dela, a sociedade civil), elas autotransformaram-se em um agente político influente. Este novo agente trouxe consigo e inseriu na esfera pública elementos éticos ligados ao cuidado, como teorizado por Carol Gilligan, frutos do modo particular como são socializadas as mulheres em nossa sociedade, que podem produzir uma nova eticidade social, bem como, em função dessa outra eticidade portada pelo Movimento, novas formas de ação política.

Tendo em vista que o nascimento de um movimento social está atrelado às experiências de desrespeito vividas individualmente e superadas coletivamente (HONNETH, 2006), a partir do movimento Mulheres unidas contra Bolsonaro e de sua sustentação em uma eticidade "feminina" assentada em empatia, defendemos no presente artigo que além das experiências individuais de desrespeito, as mulheres também são mobilizadas por experiências de desrespeito que afetam outras minorias, produzindo nelas o sentimento de que estão sendo pessoalmente injustiçadas, servindo de combustível para a ação coletiva.

Neste sentido, os objetivos do presente estudo são: identificar a natureza do movimento Mulheres unidas contra Bolsonaro e compreender por que foram as mulheres o principal grupo social a mobilizar-se contra o candidato do PSL. Estes objetivos pretendem responder ao problema: quais motivações fizeram emergir o

\footnotetext{
${ }_{4}^{4}$ Argumento semelhante foi defendido por Céli Pinto em entrevista ao Jornal Sul21 após a primeira manifestação pelo \#EleNão.
} 
movimento Mulheres unidas contra Bolsonaro e o \#EleNão durante as eleições presidenciais de 2018 no Brasil?

Nosso estudo é qualitativo e vale-se da análise do manifesto das Mulheres unidas contra Bolsonaro5, de depoimentos de integrantes dos atos e da observação participante durante os atos em Porto Alegre.

\section{Desrespeito e o surgimento de um movimento de multidão}

Em sociedade, o sujeito aprende quais as expectativas morais que pode desenvolver em cada esfera da vida. E quando as expectativas normativas de amor, respeito e estima social são frustradas ou violadas, o sujeito é acometido por um sofrimento de caráter social, embora seja experienciado individualmente. Estas experiências são qualificadas como "sociais", pois "coinciden con la experiencia de que la sociedad está haciendo algo injusto, algo injustificable" (HONNETH, 2006, p. 103).

Um movimento social, portanto, surge a partir do momento em que atores sociais que compartilham o mesmo sentimento de injustiça se conectam intersubjetivamente, buscando elaborar de maneira positiva - o que seria justo - o sentimento que surge como negação de um contexto ou experiência social de injustiça. É a elaboração coletiva de experiências individuais, "de forma que não se trate mais aqui de uma experiência isolada de um indivíduo, mas sim de um círculo intersubjetivo de sujeitos que sofrem da mesma patologia social" (SOBOTTKA, 2015, p. 30 ).

Outro elemento importante para compreendermos o surgimento de um movimento social é a esperança. Em um primeiro momento, quando o sujeito tem suas expectativas de reconhecimento frustradas, isso desencadeia nele um processo de angústia. A angústia é um afeto expectante paralisante, conforme categoriza Ernst Bloch (2005), é incapaz de colocar o indivíduo em movimento e conectá-lo a outrem, em geral, produz isolamento.

De todo modo, o fato empiricamente verificado é que os sujeitos, a despeito da angústia, agem no mundo. Isso deve-se ao fato de que, junto com a angústia, coexiste

\footnotetext{
5 O grupo de Facebook chamado Mulheres unidas contra Bolsonaro teve mais de 3,5 milhões de membras. E do grupo nasceu o movimento \#EleNão (Sul21, 2018).
} 
sempre a esperança; este afeto é o responsável por colocar os sujeitos vítimas de desrespeito ou de frustração de expectativas normativas em movimento. Conforme Bloch (2005), a esperança é o único afeto expectante capaz de fazer o ser agir no mundo na busca por fazer ser o que ainda-não-é e o que ainda-não-se-tem. Em síntese, ela é determinante para a efetivação de ações interessadas em transformar. A esperança é responsável por conectar intersubjetivamente diferentes sujeitos que expectam um mesmo objeto, nesse momento ocorre a superação do isolamento. No caso específico do \#EleNão, as redes sociais foram uma mediação decisiva para a produção da conexão intersubjetiva entre as mulheres que, sentindo-se desrespeitadas, possuíam o desejo comum de derrotar Jair Bolsonaro nas urnas e de denunciar publicamente as inúmeras formas de desrespeito presentes no discurso do candidato.

No primeiro momento da luta em busca da realização do objeto de desejo, a esperança expressa-se de modo negativo, os enunciados a respeito dos seus objetos de desejo são elaborados como negação. Isso deve-se ao fato de que, no princípio do processo de luta social, a motivação primária é a negação das circunstâncias geradoras do desrespeito, da insatisfação. Os sujeitos envolvidos na situação sabem o que não desejam, mas ainda é inexistente, ou muito precária, a consciência a respeito do que se deseja instituir no mundo, isso é produzido ao longo do processo experiencial de luta social. É nesse momento que passam a fermentar e brotar sonhos diurnos que podem dar vida (ou não) a utopias concretas, ou seja, projetos elaborados em uma gramática positiva.

Partindo desses pressupostos, pensamos que a eclosão do \#EleNão é justamente uma reação ao desrespeito e à violação de princípios éticos de um grupo social específico (o das mulheres), e isso foi decisivo para colocar os sujeitos-alvo da violação em movimento. O nome do Movimento - Mulheres unidas contra Bolsonaro ou \#EleNão - é a expressão bem-acabada de que ele nasce como negação ao candidato e ao conjunto de valores e ideias representadas e defendidas por ele. O desrespeito desperta nas mulheres o sentimento de injustiça e também - o que é decisivo para que ajam - a esperança, sentida por cada uma e compartilhada por todas, de que através da ação política coletiva é possível superar as circunstâncias geradoras do desrespeito do qual estão sendo vítimas. 
A experiência de desrespeito e a esperança de superar essa situação intersubjetivamente partilhada pode dar vida a diferentes formas de organização para a luta social. O movimento analisado, por exemplo, não apresenta as feições de um movimento social tradicional ou de um movimento de massa, marcados especialmente pela disciplina, organização vertical do poder e estabilização ao longo do tempo; as características do \#EleNão permitem que o categorizemos como um movimento de multidão.

Nesse sentido, é pertinente analisar algumas especificidades deste movimento, para isso traçaremos um paralelo entre o \#EleNão e o movimento de multidão de 2013 no Brasil, ${ }^{6}$ pois entendemos que os fenômenos apresentam similitudes, notadamente, três importantes características: intempestividade, heterogeneidade e autonomia.

O movimento \#EleNão de 2018, assim como o de 2013, é um acontecimento intempestivo no mundo, não emerge do tempo cronológico da representação e da reprodução social. Representa um rompimento com a mera reprodução da realidade social isto é, trata-se de um momento de ruptura com a mecânica confirmação do obviamente esperado, o que Bloch chama de objetivamente possível: "tudo aquilo cuja ocorrência pode ser cientificamente esperada" (BLOCH, 2005, p. 195). O Movimento é antes uma novidade que irrompe furtivamente do tempo-espaço da criação humana, composto por duas dimensões: por um lado, o tempo da criação social (Kairos) ${ }^{7}$, tempo imprevisível, instável e inconstante; por outro lado, o fecundo solo que Castoriadis

\footnotetext{
${ }^{6}$ Sobre o movimento de multidão de 2013, ver mais em Porto, 2017.

7 "Ainda vemos aqui a irredutibilidade do tempo a um tempo simplesmente calendário, porquanto, ainda que apoiado naturalmente, o tempo do fazer apresenta-se e é como interiormente diferenciado, organizado, não homogêneo, inseparável do que nele se faz. 'Há um tempo para conceber e um tempo para morrer, há um tempo para matar e um tempo para sarar' (Eclesiastes 3,1 a 8). [...] O tempo do fazer não seria o tempo do fazer e mesmo não seria tempo, se não contivesse o instante crítico, a singularidade que só é tal 'objetivamente' e só o será por e para o fazer apropriado, do qual nem a ocorrência como tal e nem o momento calendário de realização ou de aparecimento são certos ou previsíveis [...] em suma, o que os escritos hipocráticos chamam de Kairos, e a partir do que eles definem o tempo: chronos estin en ô kairos, kairos d'en ô chronos ou polus, 'o tempo é aquilo em que existe kairos (instante propício e lapso de crise, ocasião para decisão), e o kairos é aquilo que não há muito tempo'. Definição certamente muito mais essencial do que aquela que só vê no tempo a adição interminável de 'presentes' pontuais, todos idênticos: só existe tempo, dizem os escritos hipocráticos, como aquilo em que há ocasião e oportunidade para agir. O tempo do fazer deve, por conseguinte, ser instituído como contendo também singularidades não determináveis de antemão, como possibilidade do aparecimento do irregular, do acidente, do acontecimento, da ruptura da recorrência. Ele deve, em sua instituição, preservar ou controlar a emergência da alteridade como possível, e isso intrinsecamente (não como possibilidade do milagre ou do ato mágico)" (CASTORIADIS, 2010, p. 249).
} 
(2010) chama de sociedade instituinte e imaginário radical; sendo a "sociedade instituinte, o que no social-histórico é posição, criação, fazer ser" e imaginação radical “é posição, criação, fazer ser para a psiquê" (CASTORIADIS, 2010, p. 414). O nascimento intempestivo do \#EleNão, em função de suas dimensões demográficas mais de quatro milhões de membras no grupo de Facebook e dezenas de milhares de participantes nos atos de rua - impressionou a esfera pública, o que se converteu em capital simbólico para o Movimento ${ }^{8}$.

A característica da intempestividade guarda ainda outra faceta, esse tipo de movimento desaparece de modo tão imprevisto quanto surge, e o seu ressurgimento também não pode ser descartado e tão pouco projetado. Diferentemente dos movimentos sociais tradicionais, os movimentos de multidão não se estabilizam no tempo e espaço. Por isso, ele caracteriza-se principalmente por sua instabilidade e descontinuidade espaço-temporal. Diferenciando-se, por exemplo, de outras mobilizações feministas: a Marcha das Vadias marcada por sua organização centralizada em coletivos feministas situados nas cidades onde ocorre (BOENAVIDES, 2019) e o $8 \mathrm{M}$ caracterizado por sua ocorrência anual e por sua organização descentralizada, cujas diferentes ações são realizadas de modo independente pelo movimento ou coletivo que a propõe, e, ao final, produz-se um dia de luta pelas pautas das mulheres. Portanto, 8M e Marcha das Vadias são organizados e protagonizados, em geral, por mulheres militantes de movimentos sociais e são mobilizações, de certo modo, já inseridas no calendário, são um objetivamente possível.

A segunda característica típica de um movimento de multidão é a heterogeneidade. Como já pontuamos, o \#EleNão foi bastante plural. O grupo do Facebook era composto por mulheres com distintos perfis socioeconômicos e políticoideológicos; diferenças étnico-raciais, de classe social, de grau de instrução, de religião, de filiação partidária, de identificação política e de correntes do feminismo. Esta diversidade aproximou-se no sentido de formar uma coalizão em oposição ao candidato do PSL. Nos atos de rua participaram também homens e crianças.

É possível afirmar que predominou neste Movimento a "singularidade somada à cooperação, ao reconhecimento da diferença e do benefício de uma relação comum”

\footnotetext{
${ }^{8}$ Inclusive como forma de retaliação ocorreu o episódio em que o mesmo foi hackeado (O DIA, 2018).
} 
(HARDY; NEGRI apud SCHERER-WARREN, 2014, p. 419). Essa cooperação das e dos diferentes, conectados por experiências comuns de desrespeito e esperança, está assentada em uma eticidade própria que deu vida ao movimento, a saber, a ética do cuidado sobre a qual dissertaremos na seção seguinte do presente artigo.

A terceira e última característica do movimento das mulheres que queremos ressaltar é a autonomia. O \#EleNão é uma novidade porque, desde a redemocratização, os pleitos eleitorais não haviam sido tão fortemente influenciados por nenhuma organização política não tradicional. Em geral, as organizações políticas tradicionais é que operavam e protagonizavam solitariamente, pelo menos no cenário público visível, os processos eleitorais. Quando alguma outra organização político-social participava no pleito, era sempre de modo subordinado aos partidos (por exemplo, sindicatos e movimentos sociais tradicionais). O movimento das mulheres de 2018 surgiu como um novíssimo agente no terreno da sociedade civil e, a partir dali, influenciou tanto a própria sociedade civil, ao trazer o debate sobre os diversos preconceitos propagados pelo candidato Jair Bolsonaro, quanto também influenciou o xadrez da disputa eleitoral, provocando todos os agentes envolvidos no pleito a posicionarem-se de alguma forma a respeito do Movimento e de suas demandas.

Embora tenha nascido para derrotar um dos candidatos à presidência da República e as ideias defendidas por ele, o Movimento se desenvolveu e se manteve de modo independente com relação às instituições já acomodadas e instituídas na sociedade: sindicatos, partidos políticos, coletivos etc. No entanto, de modo algum negou estas instituições já cristalizadas, pelo contrário, estabeleceu relações horizontais de parceria e cooperação com várias delas (diferentemente de 2013, quando, em certo momento, predominou a negação da institucionalidade e, sobretudo, dos partidos políticos).

A não vinculação das Mulheres unidas contra Bolsonaro com algum candidato, partido ou matriz ideológica específica está ligada ao consenso estabelecido dentro do grupo de que o apoio e o voto em qualquer outro candidato(a) à presidência da República era válido, exceto no candidato do PSL. Podemos relacionar este pacto com um projeto de autonomia subjacente, em que cada mulher pode definir para si qual candidato apresenta propostas convergentes com seu projeto de vida; a coalizão, 
portanto, é formada em torno do enfrentamento ao candidato que notadamente visa instituir impeditivos à realização dos projetos de vida das mulheres e de outros grupos tidos como minoritários.

Além destas três características fundamentais, o \#EleNão tem como especificidade seu nascimento nas redes sociais a partir do grupo Mulheres unidas contra Bolsonaro e sua materialização posterior nas ruas através de atos. Assim como 2013 e a Marcha das Vadias, este Movimento utilizou o Facebook como potencializador e ferramenta para a organização das mobilizações.

No entanto, apesar de compartilhar com a Marcha das Vadias a forma de organização pela rede, o modo descentralizado e independente, o Movimento de 2018 não está apartado dos grupos tradicionais, pelo contrário. Por este motivo e pelos argumentos já apresentados, nos distanciamos do entendimento de Zanini e Mussi (2019) que apresentam o \#EleNão como uma continuidade da Marcha das Vadias. Entendemos que este Movimento não é um mero desdobramento ou derivação de algo socialmente pré-existente. Com isso, reafirmamos o argumento de que este é um Movimento intempestivo e de caráter inédito. Sendo um movimento de multidão, materializa-se de modo massivo em muitos lugares ao mesmo tempo. As dimensões longitudinais muito mais robustas e sua materialização nas mais diversas regiões do território brasileiro são outra importante diferença do \#EleNão com relação ao 8M e à Marcha das Vadias.

Há, por outro lado, uma importante similaridade entre o \#EleNão, a Marcha das Vadias e o 8M que precisa ser salientada. Essas três mobilizações ocupam o espaço público, a rua, para denunciar e resistir à precarização de suas vidas, utilizando-se, para isso, de diferentes estratégias de ação. Essas mobilizações conjugam vulnerabilidade e resistência de um modo considerado desejável por Judith Butler quando diz que "as mulheres são ao mesmo tempo vulneráveis e capazes de resistência", afirma ainda que "a vulnerabilidade e a resistência podem acontecer, acontecem, e até mesmo devem acontecer ao mesmo tempo, como vemos em certas formas de autodefesa e de instituições feministas [...] que buscam proporcionar proteção sem aumentar os poderes paternalistas" (BUTLER, 2018, p. 95). 
Nesse sentido, embora assentadas em princípios éticos distintos, de lançarem luz sobre diferentes aspectos das assimetrias de gênero, raça e classe social; e de valerem-se de distintos aliados e modos de ação, é notável que as três formas de mobilização mencionadas contribuem para a construção de um projeto emancipatório feminista. Neste artigo, porém, voltamos nossa atenção para a mobilização que, conforme compreendemos, surgiu motivada por princípios éticos ligados ao cuidado.

\section{A ética do cuidado e o levante das mulheres}

Sendo a eticidade "o conjunto de práticas e valores, vínculos éticos e instituições, que formam uma estrutura intersubjetiva de reconhecimento recíproco" (SALVADORI, 2011, p. 192), propomo-nos a pensar, no escopo do presente trabalho, que o elemento central para elucidar a eclosão do movimento \#EleNão foi a violação de princípios éticos socialmente definidos como uma ética feminina - mas não exclusiva de mulheres. Essa eticidade baseada no cuidado, afeto e preocupação para com o "outro", emerge do processo de socialização da mulher, não sendo, portanto, inata. Assim sendo, apropriamo-nos de um entendimento moral do cuidado, uma noção que entende cuidado como um conjunto de significações estruturantes de uma visão específica de mundo. Essa visão de mundo, como qualquer outra, não é natural, mas sim construída a partir e através de processos de socialização e de uma sociabilidade específica. Desta maneira, nos distanciamos de perspectivas, como as mapeadas por Tamanini (2018), que tendem a enquadrar restritivamente o cuidado como um conjunto de atividades ou então como um sentimento.

Nossa apropriação da categoria do cuidado explora o seu potencial ético-moral para estruturar um projeto de emancipação social para as mulheres em específico e para a sociedade de modo mais amplo. Nesse sentido, também nos distanciamos da interpretação elaborada por Tronto, apresentada por Tamanini (2018), para quem as atividades de cuidado, desempenhadas predominantemente por mulheres, estão ancoradas em uma ética que justifica relações de subjugação delas. Conforme apresenta Tamanini (2018), 
[...] a interpretação das mulheres como atadas à atividade mais particular de cuidar dos outros está em oposição às preocupações mais públicas e sociais dos homens. Tronto (1997) torna este argumento ainda mais contundente, ao afirmar que, na medida em que cuidar é uma maneira de "estar atento a", pode refletir um mecanismo de sobrevivência para as mulheres ou outros que estão lidando com cuidado em condições opressivas, ao invés de ser uma qualidade de valor intrínseco em si mesmo. Este aspecto costuma estar associado à outra maneira de compreender o cuidado, segundo Tronto, que é vê-lo como a ética mais apropriada para os que estão em uma posição social subordinada, como as mulheres - e outras pessoas que não estão nos corredores do poder nessa sociedade. Essas pessoas adotam uma variedade de "maneirismos diferentes" (diferença na fala, no sorrir, nas formas de linguagem corporal etc.), para servirem a seus propósitos de sobrevivência; também pode ter adotado uma atitude de "estar atento a", mas que, sob outros aspectos, pode ser compreendido como necessidade de prever os desejos de seu superior. Esta posição estrutura relações desiguais (TAMANINI, 2018, p. 46).

O quadro descrito por Tronto, revela o cuidado como uma ética desprovida de qualquer potencial emancipador. De modo diverso, com Gilligan, nossa investigação parte da compreensão de que a forma específica pela qual as mulheres são socializadas, produz relações de subordinação, mas não apenas. Também produz uma eticidade feminina, uma ética do cuidado, que contém imanentemente potencial emancipatório para as mulheres e também para a sociedade em geral.

Gilligan (2003) indica que, universal e largamente, as mulheres são responsáveis pelo primeiro cuidado das crianças, resultando com isso que "em qualquer sociedade, a personalidade feminina define-se em relação e conexão com outras pessoas, mais do que a personalidade masculina faz" (CHODOROW, 1974 apud GILLIGAN, 2003, p. 7). Assim, a primeira definição do self das meninas é assentada em empatia.

A autora esclarece que essas diferenças estão ligadas a um contexto social, onde status e poder combinados com a biologia reprodutiva delineiam a experiência de homens e mulheres e a experiência entre os sexos (GILLIGAN, 2003, p. 2). Assim, Gilligan alinha-se às perspectivas que percebem a socialização como o processo de produção e diferenciação de homens e mulheres. E argumenta:

Uma vez que é difícil dizer "diferente" sem dizer "melhor" ou "pior", uma vez que existe uma tendência para a construção de uma única escala de medição, e desde que esta escala tem sido geralmente derivada de e padronizada com base em interpretações de homens sobre dados derivados 
predominantemente ou exclusivamente de estudos de homens, psicólogos têm tendido a considerar o comportamento masculino como a "norma" e o comportamento feminino como uma espécie de desvio dessa norma. Assim, quando as mulheres não estão em conformidade com os padrões de expectativa psicológica, a conclusão tem sido geralmente que algo está errado com as mulheres (GILLIGAN, 2003, p. 14).

O que distingue a abordagem de Gilligan de outras que partem dessa mesma constatação é que a autora não entende o processo diferenciado de socialização como um problema a ser enfrentado ou o causador da desigualdade material e simbólica entre os sexos. Na avaliação dela, esses processos diferenciados de socialização produzem concepções morais distintas, e o problema está no fato de as sociedades modernas apenas atribuírem valor a uma forma de julgamento moral, a masculina.

Diferentemente das alegações de alguns críticos, Gilligan (2003) não concebe uma essência feminina assentada no cuidado, ela apenas tem por objetivo investigar "como na sociedade patriarcal vozes diferentes são formadas, valoradas, hierarquizadas e naturalizadas" (KUHNEN, 2014, p. 3). Suas considerações partem de observações empíricas que indicam a existência de perspectivas morais distintas que são produzidas socialmente a partir do sistema gênero-sexo:

Uma delas é a perspectiva "masculina", que também se pode denominar de voz padrão da moralidade, segundo a qual as decisões morais são baseadas em noções de justiça, no respeito a direitos individuais e a normas universais; a outra é a perspectiva "feminina", geralmente associada às mulheres, que Gilligan também denomina de "voz diferente" da moralidade e que aponta para um modo diverso de falar sobre problemas morais, baseado na experiência da conexão com o outro da qual resulta a atribuição de prioridade à manutenção de relacionamentos de cuidado na tomada de decisões morais (KUHNEN, 2014, p. 1).

A partir dessa constatação, Gilligan (2003) defende que esses padrões coexistam, que homens e mulheres possam valer-se tanto da ética do cuidado quanto de uma ética da justiça e do direito como padrões válidos de julgamento moral, sem hierarquias.

E, conforme Kuhnen (2014, p. 6),

[...] a perspectiva do cuidado, por meio da valorização de sentimentos morais, como empatia, altruísmo e reconhecimento da conexão com o outro, 
contribui, assim, para superar a indiferença que pode estar presente na perspectiva da justiça, baseada essencialmente na autonomia, individualização e separação.

E, de acordo com Gilligan (2003), em termos de uma estrutura democrática, o cuidado deixa de ser entendido como uma ética feminina para ser percebido como uma ética humana possível.

Há, nesse conjunto de princípios éticos do cuidado, um elemento fundamental, que é uma espécie de peça faltante no quebra-cabeça da teorização honnethiana sobre liberdade social. Segundo Honneth (2015, p. 85), "a aspiração à liberdade deixa de ser um elemento da experiência puramente subjetiva no momento em que o sujeito se encontra com outros sujeitos cujos objetivos se comportam de maneira complementar aos próprios".

Evidencia-se que um dos requisitos para a realização da liberdade social é a existência de sujeitos socializados eticamente para abrirem-se ao "outro", no sentido de perceber esse "outro" como um parceiro digno de reconhecimento; e não como um competidor, meio ou empecilho para a realização própria, pelo contrário, a realização pessoal de cada um depende irremediavelmente de reconhecimento do "outro". Por outro lado, o diagnóstico mais comum das sociedades modernas contemporâneas é a predominância de uma sociabilidade produtora de sujeitos cada vez mais atomizados, desconectados uns dos outros; talvez a célebre frase de Sartre, "o inferno são os outros", ilustre resumidamente a situação atual.

Pensamos existir parcialidade, ou mesmo cegueira, nos diagnósticos que apenas observam "individualismo" e "competição" nas sociabilidades contemporâneas. Existem outras formas de sociabilidade nestas sociedades, porém ocorrem fora do kósmos masculino. Talvez aí encontremos a explicação para a cegueira. Ao adotarmos lentes teóricas feministas, uma nova - e ao mesmo tempo antiga - dimensão do mundo social é descortinada.

Como já indicado, a ética do cuidado fruto da socialização das mulheres tem como princípio central justamente a abertura para o "outro", mais do que isso, a preocupação e inclusão do "outro" - muito embora o sujeito do cuidado por vezes não corresponda simetricamente ao reconhecimento, incorrendo em desrespeito. Essa 
forma diferente de ver, narrar, estar e se relacionar com e no mundo, antes restrita à esfera privada da vida, agora com mais força parece estar estruturando a ação das mulheres também na esfera pública.

Zanini e Mussi (2019, p. 8) afirmam que o protagonismo das mulheres organizadas em torno do \#EleNão deve ser compreendido de dois modos: primeiro, "as organizações e movimentos feministas atuam para defesa de seus interesses históricos específicos (pelos direitos reprodutivos, no combate à violência, pela ampliação da participação política, para citar alguns)"; segundo, sentem, por isso, a "necessidade de assumir a dianteira nas mobilizações mais gerais contra o ascenso eleitoral de políticos de extrema-direita, antifeministas, mas não apenas". Concordamos com a primeira afirmação das autoras sobre a necessidade das mulheres em defender seus "interesses históricos"; observamos, no entanto, que, para além de seus interesses de grupo, as mulheres também incluíram pautas e demandas de grupos aliados e ou interseccionados, como negros, indígenas, LGBTs etc.

Entretanto, divergimos de Zanini e Mussi (2019) em relação à justificativa pela qual as mulheres protagonizaram a mobilização contra Bolsonaro. Entendemos que a compreensão desse fenômeno não se esgota em uma relação de causa e efeito resistência como resultado do ataque direto às reivindicações feministas. Por isso, buscamos compreender o \#EleNão enquanto um levante de mulheres cujos princípios éticos de vida foram violados pelo projeto social de desrespeito apresentado pelo candidato do PSL através de suas diversas declarações já exemplificadas neste artigo.

Igualmente, é possível verificar o sentimento de desrespeito causado nas mulheres pelas declarações dele em alguns excertos do Manifesto publicado no Facebook pelas Mulheres unidas contra Bolsonaro: "Estamos, hoje, juntas e de cabeça erguida nas ruas de todo o Brasil porque um candidato à presidência do país, com um discurso fundado no ódio, na intolerância, no autoritarismo e no atraso, ameaça nossas conquistas e nossa já difícil existência"; e também na declaração de Heloisa Costa, integrante do Movimento: "Ele não por conta da misoginia, porque ele é preconceituoso. [...] O cara quer matar as pessoas. Se você é do bem, se você é a favor da humanidade, é ele não!” (BIBLIOO, 2018). 
Benhabib (1987) destaca que, ao identificar o julgamento moral das mulheres como sendo "mais contextual, mais imerso nos pormenores dos relacionamentos e narrativas", Gilligan chama a atenção para o fato de que "a contextualidade, narratividade e especificidade do julgamento moral das mulheres não é sinal de fraqueza ou deficiência, mas manifestação de uma visão de maturidade moral que encara o eu como imerso numa rede de relacionamentos com os outros" (BENHABIB, 1987, p. 88). Cremos que a capacidade das mulheres de perceberem-se irremediavelmente enredadas em uma "rede de relacionamentos com os outros", fruto da eticidade assentada no cuidado, possibilitou às mulheres mobilizarem-se no pleito eleitoral tendo como pano de fundo a reivindicação por liberdade de natureza social e, por conseguinte, em aliança com outros grupos alvo de opressões sociais e de discursos de ódio. Isso aparece no manifesto das Mulheres Unidas contra Bolsonaro ao também vincularem a defesa desses grupos:

\footnotetext{
Jair Bolsonaro despreza negros, indígenas, homossexuais e todas as que lutam em defesa dos direitos das mulheres. Considera quilombolas "vagabundos". Faz apologia à cultura do estupro. Diz que o nascimento de sua única filha mulher foi uma "fraquejada". Insiste que não há nada a fazer quanto à diferença salarial entre homens e mulheres. Para ele, dar "porrada" em meninos impede que eles "se tornem" gays. Seu vice na chapa, o General Mourão, declarou que famílias criadas por mães e avós são fábricas de desajustados (MULHERES, 2018).
}

Pensamos que a busca por autonomia é outro elemento motivador das mulheres engajadas no \#EleNão para o estabelecimento de parcerias simétricas com outros grupos sociais oprimidos. Estreitamente ligada à liberdade social, a autonomia individual, entendida como possibilidade do sujeito poder elaborar e realizar o seu projeto de vida (SOBOTTKA, 2015), está decisivamente vinculada à realização também da autonomia dos parceiros de interação: “el desarrollo y la realización de la autonomía individual sólo es posible, en cierto sentido, cuando todos los sujetos reunen las precondiciones sociales para realizar sus objetivos vitales sin desventajas injustificables y con la mayor libertad posible" (HONNETH, 2006, p. 192). Ou seja, enquanto persistir a opressão a algum grupo social, não existirá condições para a realização plena da autonomia. E, ao que tudo indica, há por parte do Movimento \#EleNão, pelo menos em 
nível intuitivo, a consciência disso; onde a inclusão de parceiros é um ato ético, e não utilitário.

Tal alinhamento pode ser verificado, por exemplo, na fala de Kelli Mafort, integrante do Movimento \#EleNão: "Vamos às ruas para lutar, lutar contra ele, pela terra, por trabalho, por moradia e igualdade" (MST, 2018). Em sua fala, evidencia-se, primeiramente, a negação ao candidato que representa o bloqueio à autonomia e, em segundo lugar, o esboço de um discurso positivo, em que são incluídas pautas que transbordam a agenda pontual de lutas feministas e, subjacente a elas, o reconhecimento de outros grupos sociais como parceiros.

Nessa direção, a vitória de Bolsonaro nas urnas apresenta às mulheres que se mobilizaram contra sua candidatura a necessidade de converter a negação em um projeto positivo, em princípios normativos que sejam capazes de mantê-las agregadas no sentido de fazer frente aos possíveis retrocessos já antecipados, por exemplo, pelas declarações da pastora Damares Alves, Ministra da pasta da Mulher, Família e Direitos Humanos. Quando questionada sobre abuso sexual, afirmou: "Vamos tratar meninas como princesas e meninos como príncipes" (DIÁRIO, 2018). E, após reunião da equipe de transição do governo, defendeu que há projetos interessantes tramitando no Congresso: "O mais importante que vamos estar trabalhando é a questão do estatuto do nascituro. Vamos estabelecer políticas públicas para o bebê na barriga da mãe" (DIÁRIO, 2018). Estas declarações são apenas dois exemplos de uma série de manifestações públicas da ministra que contrariam os anseios e demandas dos movimentos feministas.

Ao tratar da importância do poder para a teoria feminista, Amy Allen (1999) destaca que ele se expressa enquanto o poder que os homens exercem sobre as mulheres (power-over), enquanto a capacidade individual que as mulheres têm para resistir (power-to) e na condição de solidariedade, uma capacidade de ação coletiva que é construída pelas mulheres a partir da formação de uma coalização política com outras mulheres e com homens também (power-with). Nesse sentido, o movimento Mulheres unidas contra Bolsonaro e o \#EleNão foram espaços em que, a partir de laços de solidariedade, criou-se uma coalisão política socialmente ampla. Estes laços são

9 Declarações datadas de 11 de dezembro de 2018 (DIÁRIO DO NORDESTE, 2018). 
fundamentais para a construção de um projeto ético-democrático feminista, cujas reivindicações normativas têm como base ética o cuidado e a inclusão do "outro" na possibilidade de realização do projeto de vida de cada um e uma.

Como ilustra um dos símbolos que viralizou nas redes sociais, após a divulgação do resultado do pleito: "Ninguém solta a mão de ninguém" foi a frase dita por uma mulher paulista a sua filha, que a converteu em arte e compartilhou nas redes sociais. Esta expressão de afeto, acolhimento e coalizão política, tornou-se símbolo das mulheres que se comprometeram em enfrentar as políticas discriminatórias e restritivas à liberdade social anunciadas pelo então presidente eleito Jair Bolsonaro e pelos parlamentares eleitos integrantes de sua base aliada.

\section{Considerações finais}

Ao longo do presente artigo, buscamos analisar de modo introdutório o movimento Mulheres Unidas contra Bolsonaro ou \#EleNão a partir de, basicamente, duas chaves interpretativas. Primeiro, procuramos investigar a natureza desse Movimento focalizando suas especificidades e seu caráter de novidade na esfera pública. Para isso, mobilizamos a categoria de movimento de multidão, traçamos paralelos com o movimento eclodido em 2013 no Brasil e o distinguimos da Marcha das Vadias e do 8M. Em Honneth (2006; 2015) e Bloch (2005), buscamos o suporte interpretativo para compreender as motivações para a eclosão do levante feminino e feminista contra o então candidato a presidente da República Jair Bolsonaro: as agressões proferidas por ele contra as mulheres e outras minoria violou a eticidade delas - assentada em princípios normativos ligados ao cuidado -, produzindo o sentimento de violação e injustiça, que, conectado à esperança em superar e transformar o contexto gerador da violação, foi o principal motivador para a mobilização.

$\mathrm{Na}$ segunda parte do texto, o esforço concentrou-se em analisar de modo focalizado a importância da ética do cuidado para a mobilização das mulheres, para compreender o protagonismo delas no contexto eleitoral encabeçando a costura de uma coalizão ampla de luta. Pois, na busca por combater a regressão político-social 
emergente no Brasil no tempo presente, o \#EleNão demonstrou-se capaz - desde uma perspectiva feminista heterogênea - de realizar a difícil tarefa de agregar setores políticos que, embora pertençam ao mesmo campo ideológico, têm sido incapazes de cooperar entre si no sentido de construir uma frente de luta ampla, unificada e, ao mesmo tempo, plural. As ações e a leitura conjuntural das Mulheres unidas contra Bolsonaro foram balizadas por noções fortes de alteridade, empatia, solidariedade e cooperação, o que propiciou o agregamento de diferentes organizações e perspectivas políticas.

Diferentemente das organizações políticas tradicionais (partidos, sindicatos, etc.) que têm demonstrado incapacidade para a construção de coalizões em função de estarem orientadas por princípios ético-normativos ligados à racionalidade neoliberal ${ }^{10}$. Em geral, o que predomina, embora o discurso seja contrário, é a crença que cada organização tem de que é a portadora da verdade mais luminosa. O que desencadeia uma lógica de relações de competição e disputa acerca de ideias, recursos e militantes para suas bases. Ocorre uma espécie de colonização do imaginário dessas organizações por significações tipicamente neoliberais. Nesse caso, o que se verifica é que estão orientadas por uma racionalidade atrelada a uma ética masculina, assentada em separação, disputa e individualização.

Na medida em que as novidades no campo das lutas sociais vêm sendo, cada vez mais, protagonizadas por mulheres, cria-se um tensionamento na esfera pública com a eticidade instituída, colocando a ética do cuidado como um conjunto de princípios democraticamente possíveis. E, mais do que isso, como já visto, existem afinidades eletivas entre ética do cuidado, liberdade social e autonomia, portanto, a presença das mulheres na esfera pública demonstra forte potencialidade para reanimar e fortalecer a utopia ${ }^{11}$ da emancipação social.

\footnotetext{
${ }^{10}$ Ver mais em Brown, 2015.

${ }^{11} \mathrm{O}$ sentido de utopia aqui invocado é o teorizado por Bloch (2005, p. 195): "Enquanto a realidade não for completamente determinada, enquanto ela contiver possibilidades inconclusas em novas germinações e novos espaços de conformação, enquanto for assim, não poderá proceder da realidade meramente fática qualquer objeção absoluta contra a utopia. Poderá haver objeções contra utopias malfeitas, isto é, contra aquelas que divagam abstratamente, incorretamente mediadas. Contudo, exatamente a utopia concreta tem na realidade do processo um correspondente: o do novum mediado. Somente essa realidade do processo e não uma facticidade absolutizada e reificada, arrancada de dentro da realidade, pode formular um juízo a respeito dos sonhos utópicos ou rebaixá-los a mera ilusão.
} 


\section{Referências}

ALLEN, Amy. The power of feminist theory: domination, resistance, solidarity. Colorado: Westview Press, 1999.

BENHABIB, Seyla. O outro generalizado e o outro concreto: a controvérsia KohlbergGilligan e a teoria feminista. In BENHABIB, Seyla; CORNELL, Drucilla (coords.). Feminismo como crítica da modernidade. Rio de Janeiro: Rosa dos tempos, 1987.

BIBLIOO. Ato Mulheres contra Bolsonaro na Cinelândia - \#Elenão, 2018. Disponível em: <https://www.youtube.com/watch?v=cBdLrGgYfik>. Acesso em: 02/06/2020.

BLOCH, Ernst. O princípio esperança. Rio de Janeiro, EdUERJ, Contraponto, v. 1, 2005 .

BOENAVIDES, Débora Luciene Porto. Ressignificar e resistir: a Marcha das Vadias e a apropriação da denominação opressora. In: Revista Estudos Feministas, 27(2): 1-9, 2019.

BROWN, Wendy. Undoing the demos: neoliberalism's stealth revolution. New York: Zone Books, 2015.

BUTLER, Judith. Corpos em aliança e a política das ruas: notas para uma teoria performativa de assembleia. Rio de Janeiro: Civilização Brasileira, 2018.

CARTA CAPITAL. Bolsonaro em 25 frases polêmicas, 2018. Disponível em: <https://www.cartacapital.com.br/politica/bolsonaro-em-25-frases-polemicas/>.

Acesso em: 31/05/2020.

CASTORIADIS, Cornelius. A instituição imaginária da sociedade. São Paulo: Paz e Terra, 2010.

DIA, O. Grupo 'Mulheres Unidas contra Bolsonaro' é hackeado e administradoras têm comunicação cortada, 2018. Disponível em: <https://odia.ig.com.br/eleicoes/2018/o9/5575479-grupo-mulheres-unidas-contrabolsonaro-e-hackeado-e-administradoras-tem-comunicacao-cortada.html\#foto=1>. Acesso em: 13/12/2018.

DIÁRIO DO NORDESTE. Damares Alves: veja frases polêmicas da futura ministra da Mulher, Família e Direitos Humanos, 2018. Disponível em: <http://www.diariodonordeste.verdesmares.com.br/editorias/politica/online/damaresalves-veja-frases-polemicas-da-futura-ministra-da-mulher-familia-e-direitos-humanos1.2037042>. Acesso em: 13/12/2018. 
GILLIGAN, Carol. In a different voice. USA: Harvard University Press, 2003.

HONNETH, Axel. Redistribución como reconocimiento: Respuesta a Nancy Fraser. In FRASER, Nancy; HONNETH, Axel. ¿Redistribución o reconocimiento? Um debate político-filosófico. Madrid: Ediciones Morata, 2006.

HONNETH, Axel. Atualização histórica: o direito da liberdade. In HONNETH, Axel. O direito da liberdade. São Paulo: Martins Fontes, 2015.

KUHNEN, Tânia Aparecida. A ética do cuidado como teoria feminista. In Anais do Simpósio Gênero e Políticas Públicas, Londrina, 2014. Disponível em: http://www.uel.br/eventos/gpp/pages/arquivos/GT10_T\%C3\%A2nia\%2oAparecida\%20 Kuhnen.pdf. Acesso em: 06/01/2019.

MST. Mulheres, LGBTs e juventude do MST se juntam à mobilização “EleNão", 2018. Disponível em: <https://mst.org.br/2018/o9/28/mulheres-lgbts-e-juventude-domst-se-juntam-a-mobilizacao-elenao/>. Acesso em: 02/o6/2020.

MULHERES unidas contra Bolsonaro. Manifesto das Mulheres Unidas contra Bolsonaro. Facebook, 2018.

PORTO, Douglas Michel Ribeiro. O Princípio Esperança e o movimento de multidão de 2013. Porto Alegre: Dissertação de Mestrado em Ciências Sociais. Pontifícia Universidade Católica do Rio Grande do Sul, Programa de Pós-graduação em Ciências Sociais, 2017.

SALVADORI, Mateus. HONNETH, Axel. Luta por reconhecimento: a gramática moral dos conflitos sociais. In Conjectura, 16(1): 189-192, 2011.

SCHERER-WARREN, Ilse. Manifestações de rua no Brasil em 2013: encontros e desencontros na política. In Caderno CRH, 27(71): 417-429, 2014.

SOBOTTKA, Emil Albert. Reconhecimento: novas abordagens em teoria crítica. São Paulo: Annablume, 2015.

SUL21. 'Não se faz mais política sem mulher no Brasil de agora em diante', 2018. Disponível em: https://www.sul21.com.br/ultimas-noticias/politica/2018/10/nao-se-fazmais-politica-sem-mulher-no-brasil-de-agora-em-diante/. Acesso em: 07/12/2018.

TAMANINI, Marlene. Para uma epistemologia do cuidado: teorias e políticas. In TAMANINI, Marlene et. al. (org.). O cuidado em cena: desafios políticos, teóricos e práticos. Florianópolis: UDESC, 2018.

ZANINI, Débora; MUSSI, Daniela. \#Eles não! O confronto eleitoral feminino contra Trump e Bolsonaro. In Anais 43ํㅡㄹ Encontro Anual da Anpocs, Caxambu, 2019. 
Disponível em: <https://anpocs.com/index.php/encontros/papers/43-encontro-anualda-anpocs/st-11/st24-6>. Acesso em: 31/05/2020. 